\title{
SMS based Bus Tracking System using Open Source Technologies
}

\author{
R.Maruthi \\ Associate Professor, Department of MCA \\ SSN College of Engineering,Chennai
}

\author{
C.Jayakumari \\ Associate Professor, Department of MCA \\ SSN College of Engineering, Chennai
}

\begin{abstract}
A bus tracker application to track a bus using GPS transceiver has been proposed in this paper. The objective of this work is to develop a system that manages and controls the transport using a tracking device to know the scheduled vehicle and the current location of the vehicle via SMS using a GPS tracking device. It uses the satellite technology and advanced computer modeling to track vehicles on their routes. The system is implemented using a WAMP server and an application to track the bus is written in PHP with MYSQL as a database for storing the necessary details.
\end{abstract}

\section{Keywords}

Bus tracker, GPS receiver, WAMP server, SMS Enabler

\section{INTRODUCTION}

The vehicle tracking system is used in a wide variety of applications. Most of the tracking systems use geographic position and time information from the global positioning satellites. GSM(Global system of Mobile Communications) and GPS(Global Positioning System) based vehicle location and tracking system will provide effective, real time vehicle location, mapping and reporting [2]. It also provides the most up-to-date information about the ongoing trips. This system incorporates a hardware device (GPS receivers) installed in the bus. The GPS unit placed in the bus receives signal from any four visible satellites among the constellation of satellites in the space. The GPS unit consists of a receiver, a controller/processing unit and a communication interface.

The basic function of the device in the bus is to acquire and transmit the position of the bus to the server at a fixed interval of time. Microcontroller unit forms the heart of the tracking unit, which acquires and process the position data from the GPS module. The communication interface is responsible for receiving the signals from the satellites and sending the information to the server [1].

The Vehicle Tracking System developed by C-DAC, Thiruvananthapuram employs a GPS (Global Positioning System) receiver to identify the location of the vehicle and transmit the information to the base server over the GSM (Global System for Mobile Communication) network[5]. In paper [3], architecture for tracking the vehicle is developed using the wireless sensor devices for detecting the theft of the vehicle .But this application does not track the vehicle if it is away from the parking lot and also for the Vehicle in motion. Vehicle Tracking systems uses a wide range of new technologies and communication networks including General Packet Radio Service (GPRS), Global System for Mobile Communication (GSM), the Internet or the World Wide Web and Global Positioning System (GPS)[4]. The following section discusses the framework for a bus tracking system using GPS and GSM technologies. Most of the vehicle tracking system is web based application or else a LCD display. The table-2 shows some of the existing applications for tracking a vehicle.

Table-1 Existing tracking Systems

\begin{tabular}{|c|c|c|}
\hline S.No & $\begin{array}{l}\text { Existing } \\
\text { Systems }\end{array}$ & Limitations \\
\hline 1 & $\begin{array}{l}\text { Intelligent } \\
\text { vehicle } \\
\text { tracking } \\
\text { system[1] }\end{array}$ & $\begin{array}{l}\text { Not mobile based - Uses a vehicle } \\
\text { unit and a tracking server. }\end{array}$ \\
\hline 2 & $\begin{array}{lr}\text { Tracking } & \text { using } \\
\text { GPS } & \text { and } \\
\text { GSM[2] } & \end{array}$ & $\begin{array}{l}\text { Mobile based -sms is sent by the } \\
\text { vehicle unit to know the location of } \\
\text { the vehicle. The user can also send } \\
\text { a information to switch of the } \\
\text { vehicle. No tracking server is used } \\
\text { in this system for further } \\
\text { processing. }\end{array}$ \\
\hline 3 & $\begin{array}{l}\text { Tracking } \\
\text { vehicles using } \\
\text { wireless sensor } \\
\text { devices[3] }\end{array}$ & $\begin{array}{l}\text { Not mobile based - wireless sensor } \\
\text { node, which is installed on the } \\
\text { vehicle; gateway (GW) node, } \\
\text { which is responsible for receiving } \\
\text { data from the sensor nodes and } \\
\text { sending it to the central server. }\end{array}$ \\
\hline 4 & $\begin{array}{l}\text { Ubiquitous } \\
\text { GPS Vehicle } \\
\text { Tracking [4] }\end{array}$ & $\begin{array}{l}\text { Web based application- send SMS } \\
\text { alerts to the user`s cell phone when } \\
\text { an event occurs like when the } \\
\text { driver over speeds or exits the pre- } \\
\text { defined geo-fence area. }\end{array}$ \\
\hline 5 & $\begin{array}{l}\text { Tracking } \\
\text { system } \\
\text { employs GSM } \\
\text { and GPS [5] }\end{array}$ & $\begin{array}{l}\text { Not mobile based }- \text { web based } \\
\text { application. The user can know the } \\
\text { location by entering into the } \\
\text { appropriate web site. }\end{array}$ \\
\hline 6 & $\begin{array}{l}\text { SMS based } \\
\text { tracking } \\
\text { attempted in } \\
\text { this study }\end{array}$ & $\begin{array}{l}\text { Mobile based-using open source } \\
\text { technologies- SMS is sent by the } \\
\text { users to know the location of the } \\
\text { bus to the central server and vice- } \\
\text { versa. }\end{array}$ \\
\hline
\end{tabular}

\section{BUS TRACKING SYSTEM}

The GPS receiver of the vehicle terminal receives and resolves the navigation message broadcasted by GPS position satellites and computes the longitude and latitude of vehicle coordinates. This information is transmitted into the server using GSM network using SMS and the information is stored in the database of the server. The users can retrieve the data on registering themselves by sending the route number and the stop name where they need an alert. When the bus reaches the particular stop, the reply from the server is the location of 
the particular bus at that time. The overall architecture of the tracking system is given in figure: 1

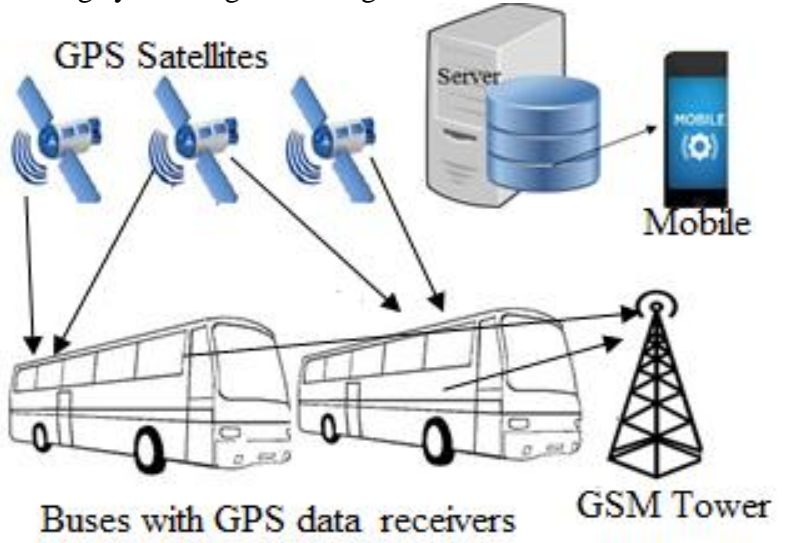

Figure-1 Overall Architecture of the tracking system

This system also has a facility for informing the change of route \& cancellations to registered users and can resolve following problems such as late arrivals, improper use of vehicles, unsafe driving habits etc. The tasks involved in the systems includes, tracking the vehicle, communicating between the tracker and server, locating the vehicle using GPS data and communicating between the user and the server.

\subsection{Tracking the Vehicle}

The vehicle is tracked by installing a special device or GPS transceivers in the vehicle. GPS works in any weather conditions, anywhere in the world, 24 hours a day. There are no subscription fees or setup charges to use GPS. A GPS receiver is capable of receiving signals from atleast three satellites in view to calculate the position. The GPS transceivers can be a Data Loggers, Data Pullers or Data Pushers depending on the type of application. The type of tracker required for this system is Data pushers. This device receives the GPS data and sends the data at regular intervals as SMS to the server. Then the server analyses the data. The GPS antenna is connected to the right jack and fixes the antennas to make sure it receives signals in the appropriate place. The SIM card is inserted properly in the corresponding slot and it receives the signals from the GSM towers to respond to the users. The positive and negative wire is connected with $12 \mathrm{~V}$ or $24 \mathrm{~V}$ vehicle power system. Then the tracker device is turned on to receive the signals from the satellite. Now the device is capable of receiving the latitude and longitude values of the location of the bus. At any point of time the GPS receiver is tuned to give the location values. A GPS transceiver is shown in figure-2. The numbers below gives the description of each of the component.
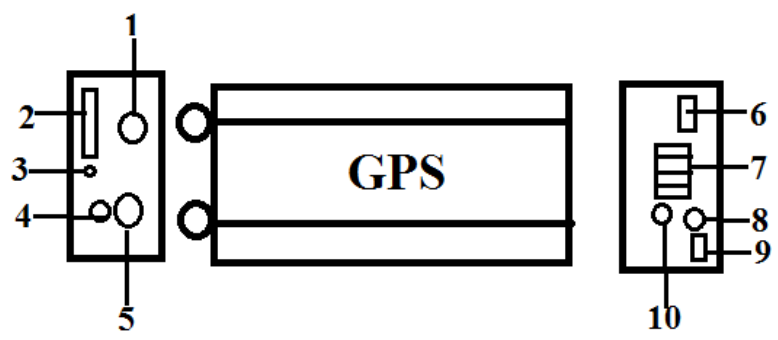

Figure-2 GPS Tracker Device

1 GSM Antenna Jack 2 Sim Card Slot
3 Pop-up switch

4 Monitor Jack

5 GPS Antenna jack

6 Sensor Jack

7 External Connection jack

8 Power/GSM/GPS

LED indicator

$9 \quad$ Back up battery and

10 Reserved switch

\subsection{Communication-Tracker and Server}

The GPS receiver is then connected to the server which manages the GPS data. Initially a set-up message is sent from the server to the tracker device to set the time interval for sending the GPS data. The tracker gives the geo-information to the server at regular time intervals in the form of SMS.

The server has to manage the messages from the tracker device and the user's request. The SMS enabler acts as an interface between the tracker and the server. The PC suite is installed in the server to make use of the SMS enabler[6] in the server. The screenshot in figure- 3 shows the format of the GPS data received by the server from the tracker via SMS enabler.

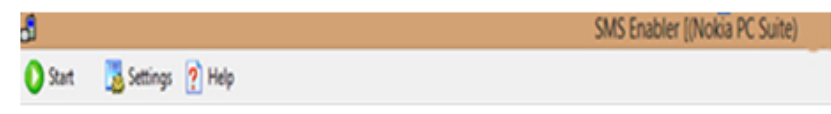

4/19/2013 07:07:51 Forwarded received sms to URL Lttp://127.0.0.1/wiki/index.php

4/19/2013 07:07:51 Received sms form; ;919994513452; sent date: 4/19/2013 07:04:55

lat:12.97764 long:080.25932 speed:060.00

$T: 19 / 04 / 1307: 03$

http://ww.wxlxy.com /GPSTracker. aspx?kev=353451841681896@7929024.80@4588280.632

Figure-3 Format of message-Tracker to the server via SMS enabler.

The SMS enabler receives the SMS data from the tracker in the vehicle. A PHP[8] code is then written to fetch the longitude and latitude values from the whole message and stores it in MYSQL database. A mapping of the location values with the location name is also done to know the location name of the vehicle. The location name, longitude and latitude values are given in table-1 for mapping the received values to the location name.

Table-1 Location Mapping

\begin{tabular}{|c|c|c|}
\hline Location Name & Latitude & Longitude \\
\hline Chennai & 12.40 & 8.30 \\
\hline Arcot & $12^{\circ} 56^{\prime}$ & $79^{\circ} 24^{\prime}$ \\
\hline Kanchipuram & $12^{\circ} 50^{\prime}$ & $79^{\circ} 45^{\prime}$ \\
\hline
\end{tabular}

The server used in this system is a WAMPServer[7]. It is a Windows web development environment which is used to create web applications with Apache2, PHP and a MySQL database. The steps to initiate the server are as follows

- Install the WAMP server and load the PHP files in the server 
- Connect the database with the PHP Script

- Connect the mobile phone using USB data cable to the server

- Synchronize mobile with PC using PC suite

- Start SMSENABLER and connect mobile using PC suite

- Start the WAMP server

Now the system is ready to receive the data from the users and the tracker devices in the buses.

\subsection{Communication-User and Server}

The user's SMS to know the location of the vehicle is then received by the server via the SMS enabler. A PHP application in the server side processes the user's request. The server fetches the location name from the database for the corresponding vehicle and sends a reply to the user. An alert can also be send to notify the updated location to the users through SMS. The location update alert is available only for the registered user.

In order to register, the user must send the registration message along with the vehicle ID and the name of the location where the user needs an alert. The user data is validated by the server and if all the details provided by the user are found correct then the user is registered and a confirmation message is sent to the user. The user also has an option to unregister when the SMS alert is no more needed. The user can send the unregister message to cancel the service.. The user has to send the SMS in a particular format to get the location. The SMS should contain a valid vehicle number and it must be a number. The user SMS is validated in the server and if the user has sent a valid SMS then the user will get a SMS reply with the current location of the requested vehicle.

\section{CONCLUSION}

There is no standard application for vehicle tracking. The applications are written to suit the needs of the scenario which exists. In this paper, a SMS based customized application to track the buses using open source technologies has been discussed. The Whole system is built on top of the existing infrastructure and it does not require any additional infrastructure for communication link. This system will be useful for all the passengers to board the bus by knowing the location of the bus through SMS. This system can also be modified to notify the number of passengers in the bus by sending SMS to the same route users. This can help the users to get into the less crowded bus in the same route.

\section{ACKNOWLEDGEMENTS}

We would like to offer our special thanks to the management of SSN Institutions for funding this project. We wish to thank all our colleagues and students for their support and encouragement throughout our project work.

\section{REFERENCES}

[1] Dr. Kamal Jain and Rahul Goel, GPS Based Low Cost Intelligent Vehicle Tracking System (IVTS), 2012 International Conference on Traffic and Transportation Engineering (ICTTE 2012) IPCSIT vol. 26 (2012) (C) (2012) IACSIT Press, Singapore.

[2] Baburao Kodavati, V.K.Raju, S.Srinivasa Rao, A.V.Prabu, T.Appa Rao, Dr.Y.V.Narayana, GSM and GPS based vehicle location and Tracking System, International Journal Research and Applications (IJERA) ISSN: 2248-9622 Vol. 1, Issue 3, pp.616- 625.

[3] Aravind, K. G.; Chakravarty, T.; Chandra, M.G.; Balamuralidhar, P., "On the architecture of vehicle tracking system using wireless sensor devices," Ultra Modern Telecommunications \& Workshops, 2009 ICUMT '09. International Conference on , vol., no., pp.1,5, 12-14 Oct. 2009.

[4] Almomani, I.M.; Alkhalil, N.Y.; Ahmad, E.M.; Jodeh, R.M., "Ubiquitous GPS vehicle tracking and management system," Applied Electrical Engineering and Computing Technologies (AEECT), 2011 IEEE Jordan Conference on , vol., no., pp.1,6, 6-8 Dec. 2011.

[5] http://www.cdactvm.in/vehicletracking.pdf, "Vehicle Tracking System developed by C-DAC, Thiruvananthapuram".

[6] SMS enabler.com, "Download software to receive SMs on a computer"

[7] http://www.wampserver.com/en/, "Download WAMP server"

[8] http://www.w3schools.com/php/, " "Tutorial on PHP to implement the system" 